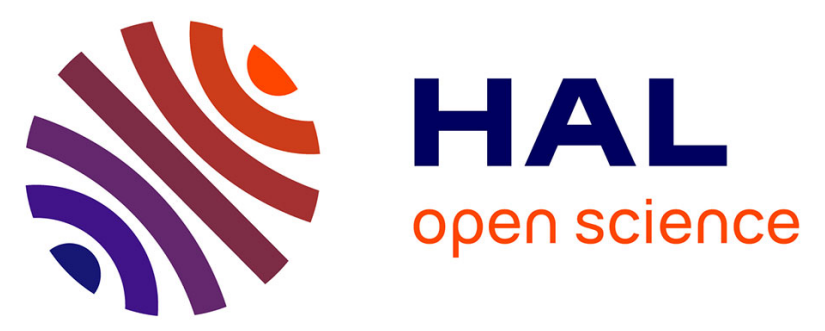

\title{
Transcrystallinity in maize tissues/polypropylene composites: First focus of the heterogeneous nucleation and growth stages versus tissue type
}

Séverine A.E. Boyer, Jean-Marc Haudin, Vivian Song, Vincent Bourassier, Patrick Navard, Cécile Barron

\section{To cite this version:}

Séverine A.E. Boyer, Jean-Marc Haudin, Vivian Song, Vincent Bourassier, Patrick Navard, et al.. Transcrystallinity in maize tissues/polypropylene composites: First focus of the heterogeneous nucleation and growth stages versus tissue type. Polymer Crystallization, 2021, 4 (1), pp.e10155. 10.1002/pcr2.10155 . hal-02967942

\section{HAL Id: hal-02967942 \\ https://hal.inrae.fr/hal-02967942}

Submitted on 7 Jan 2021

HAL is a multi-disciplinary open access archive for the deposit and dissemination of scientific research documents, whether they are published or not. The documents may come from teaching and research institutions in France or abroad, or from public or private research centers.
L'archive ouverte pluridisciplinaire HAL, est destinée au dépôt et à la diffusion de documents scientifiques de niveau recherche, publiés ou non, émanant des établissements d'enseignement et de recherche français ou étrangers, des laboratoires publics ou privés. 
To Polymer Crystallization Editorial Advisory Board

Invitation to contribute to a special issue of Polymer Crystallization

Transcrystallinity in maize tissues/polypropylene composites: first focus of the heterogeneous nucleation and growth stages versus tissue type

Séverine A.E. Boyer ${ }^{1}$, Jean-Marc Haudin ${ }^{1}$, Vivian Song ${ }^{1}$, Vincent Bourassier ${ }^{1}$, Patrick Navard ${ }^{1}$, Cécile Barron ${ }^{2}$

1 Mines ParisTech, PSL-Research University, CEMEF-Centre de Mise en Forme des Matériauxa ${ }^{a}$, UMR CNRS 7635, CS 10207, Rue Claude Daunesse, 06904, Sophia Antipolis Cedex, France

2 IATE, Univ Montpellier, Cirad, INRAE, Institut Agro, 34060 Montpellier, France

Correspondence

Séverine A.E. Boyer and Jean-Marc Haudin, MINES ParisTech, PSL Research University, CEMEF-Centre de Mise en Forme des Matériaux, CNRS UMR 7635, CS 10207, 06904 Sophia Antipolis Cedex, France

Email: severine.boyer@mines-paristech.fr and jean-marc.haudin@ mines-paristech.fr

ORCID

Séverine A.E. Boyer: http://orcid.org/0000-0002-3271-3465

Jean-Marc Haudin: https://orcid.org/0000-0003-4052-2981

${ }^{\text {a }}$ Member of the European Polysaccharide Network of Excellence (EPNOE), www.epnoe.eu 
The improvement of cellulosic biomass-polymer composites needs to evaluate what occurs at the biomass-matrix interface during crystallization. Different well-defined maize tissues were obtained by original dry fractionation processes, without chemical treatment. Their morphological features were identified by optical and scanning electron microscopies. For each type of tissue, a small fragment was sandwiched between two films of isotactic polypropylene. The composite was subjected to quiescent isothermal conditions, followed in-situ by polarized optical microscopy. Focus of the heterogeneous nucleation at the surface of maize tissues showed that in all cases, more or less numerous semi-crystalline entities originated from the tissue surface, indicating a moderate nucleating activity. Different crystallization behaviors were observed as a function of the tissue. Growth rates of surface layers were generally higher that the growth rates of bulk spherulites. The differences were small, but significant. They were discussed within the frame of kinetic theory of growth.

Key words

crystallization, composite, maize tissue, isotactic polypropylene, transcrystallinity 
Introduction

Natural and renewable fillers are more and more used to manufacture composites with a polymer matrix. For instance, the replacement of heavy glass fibres is an important asset in the automotive industry where weight is a critical issue for performances and energy savings. ${ }^{[1]}$

There have been numerous trials for preparing composites and studying mostly mechanical properties in bulk state with different biomass sources (see some recent reviews ${ }^{[2-6]}$ ). Many types of plant organs can be used as fillers. For polymer composites, these organs should be elongated in order to offer the best mechanical properties of the final products. These fillers are generally called fibres, even if this term can bring some confusion regarding which part of the plant is considered. These fibres can be extracted from different locations in the plant. They can originate from organs having no structural role like cotton hairs, but also from cell structures of various natures as in wood or from the inner bark situated beneath the outside bark skin of plants (case of bast fibres extracted from flax, hemp, or ramie). Elongated plant-based fillers can also be extracted from leaves, as for sisal, curauá or banana. Fruits can also provide fibrelike fillers such as coir fibres which are extracted from the husk of a coconut. In all cases, these plant fibres can be individual cells (case of cotton) or in the form of cell bundles. They have a variable content of cellulose, hemicelluloses, pectins and lignin. Their complex and hierarchical supramolecular bio-assembly brings stiffness and strength to plants.

Although there are a large number of articles dealing with plant-based filler-polypropylene composites, very few are studying the crystallization of the matrix $\cdot{ }^{[7-9]}$ However, among the physical phenomena of interest, crystallization should have a special place, since it partly controls the properties of the matrix and of the interface. An important issue is: do the fillers promote heterogeneous nucleation at their surface, thus accelerating the crystallization of the polymer matrix? Three types of morphological behavior can be distinguished: ${ }^{[10]}$ i) inactivity of the surfaces: spherulites appear only in the polymer volume; (ii) medium activity of the surfaces: a few half-spherulites are created from surface nuclei; (iii) high activity of the surfaces: if many heterogeneous nuclei are activated at the surfaces, their proximity imposes that entities emanating from these nuclei grow preferentially normal to the surface, leading to what is usually called transcrystalline zones. This interpretation of transcrystallinity, due to Fitchmun and Newman, ${ }^{[11]}$ is based only on geometrical considerations, and does not require the occurrence of flow or temperature gradients. This definition of "pure" transcrystallinity will 
be retained in the present paper. Crystallization of a semi-crystalline polymer, e.g., isotactic polypropylene (iPP), on a crystalline substrate has been interpreted in terms of epitaxy. ${ }^{[12]}$ Unfortunately, this crystallographic interpretation does not seem to be sufficient to fully understand transcrystallinity and its possible role on mechanical properties. Interfacial interactions between polymer matrix and filler could modify mechanical performances. ${ }^{[13]}$ According to Quan et al., ${ }^{[14]}$ the scientific community remains unsure of the mechanisms of transcrystallinity and controversy continues to exist whether transcrystallinity has positive, negative, or even no effects on composite mechanical properties.

Native cellulose (having a cellulose I crystalline structure) seems to have a clear effect on the crystallization of iPP. For instance, cellulose nanocrystals (CNC) have a strong nucleating effect, as indicated by the increase of crystallization temperature and rate. ${ }^{[15-16]}$ As a film substrate (instead of individual particles), $\mathrm{CNC}$ can even promote transcrystallization of iPP. ${ }^{[17]}$ Lignin is also an important parameter. For six different lignocellulosic fillers, Girones et al. ${ }^{[18]}$ established an inverse relationship between the matrix crystallization kinetics and the lignin content of the fillers, the more effective to enhance crystallization kinetics being pure cellulose (cotton), whereas pure lignin has no effect. Some of the fillers, especially cotton, exhibited transcrystallininity at their surface. Transcrystallinity at the surface of cotton fibers was also described by Gray ${ }^{[19]}$ and Ning et al. ${ }^{[13]}$ Moreover, Gray showed that native cellulose fibers (cellulose I) induced transcrystallinity, while regenerated cellulose fibers (cellulose II) did not. Several papers have reported that natural fibers such as jute, flax, sisal or kenaf could induce transcrystallinity in iPP. ${ }^{[8-9,14,20-22]}$ The effect of chemical treatments on the capacity to induce transcrystallinity is also a common object of debate. ${ }^{[14,21-24]}$ In this aspect, some controversial results have been reported, and whilst some works report that the rate of growth was higher for composites coupled with maleic anhydride grafted polypropylene MA-g-PP, ${ }^{[22,25]}$ others reported that treated fibers had no effect. ${ }^{[9]}$

This bibliographic survey has identified some trends, but it must be recognized that there is no rational picture regarding the way lignocellulosic fillers act on polypropylene. A general reason for such a disparity of results lies on the many parameters that can affect nucleation, from chemical composition to surface roughness, geometry and size of fillers. In the papers concerning PP crystallization, other reasons for these inconsistent results could be: (i) that none of these studies used the same polymer matrix; (ii) the way compatibilization is treated (even if 
most methods are based on the addition of maleic anhydride, the compatibilizer can be added as a third component, used directly as the matrix or grafted onto the filler), (iii) that the fillers used are of different nature and structure, coming from different tissues and having different compositions at their surface.

Using a single matrix taken as a 'model system, ${ }^{[26]}$ with no compatibilizer, the present paper compares the crystallization of a polypropylene sample in the bulk and at the surfaces of different, well characterized tissues, the crystalline growth rate being chosen as a relevant parameter. The originality of this work is to use as fillers different tissues from well-known maize plant. Thus, by exclusively studying one plant and its different tissues, one could be able to observe how the different tissues are influencing polymer transcrystallinity.

\section{Experimental}

\subsection{Polymer}

The isotactic polypropylene (iPP) used as polymer matrix was an injection-molding grade (from Atofina now Arkema, Colombes, France) under the reference 3250 MR1 (equivalent to PPH 9081, Total Petrochemicals, Féluy, Belgium). Molecular parameters are: $M_{n}=42500 \mathrm{~g} \mathrm{~mol}^{-1}$, $M_{w}=213000 \mathrm{~g} \mathrm{~mol}^{-1}, M_{w} / M_{n}=5$, and isotacticity index $=0.97$. The Melt Flow Index of $25 \mathrm{~g}$ $(10 \mathrm{~min})^{-1}$ was determined according to the ISO 1133 method under $230^{\circ} \mathrm{C} / 2.16 \mathrm{~kg}$ conditions. This polymer was selected because it crystallizes in spherulites easily observable by optical microscopy.

\subsection{Maize samples}

The maize samples were extracted from the internodes of maize stems (Figure 1). A maize internode is composed of two main anatomical parts: the pith, the inner part constituted of some vascular bundles spread in large parenchyma cells, and the rind, composed of closely spaced vascular bundles embedded in cortical parenchyma and sclerenchyma tissues. Epidermis constitues the thin external protective layer. 

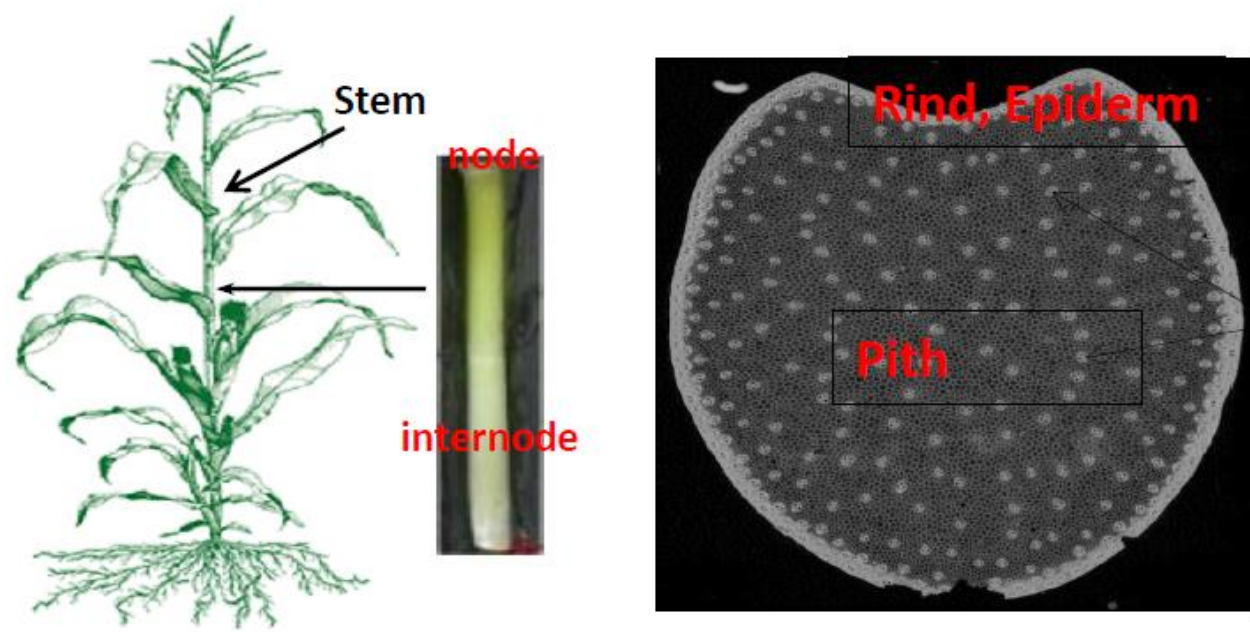

Vascular bundles

FIGURE 1 Anatomy of a maize stem

Maize stems were obtained as a by-product of maize grain harvest and their internodes were isolated manually and cut in $2 \mathrm{~cm}$ long rods before to be fractionated. Maize stem tissues were then isolated by density sorting after knife milling. ${ }^{[27]}$ As density sorting is efficient for particle of same size range, a preliminary step of sieving was applied. Pieces of pith (light particles) and rind (dense particles) were obtained as the two extreme samples in the gravity separator. Vascular bundles from pith could be dissociated from parenchyma after grinding and recovered in the lighter samples, whereas vascular bundles from the rind were obtained in an intermediate fraction from the gravity separator. The dry fractionation processes show a low impact on tissue structure and composition, as no chemicals are added. More details will be found in Results part.

\subsection{Composite preparation}

All the fillers were dried at $70^{\circ} \mathrm{C}$ for 24 hours before being used to prepare composite samples.

Glass slides and cover slips were cleaned with ethanol to remove impurities. A small sample of polymer film was first put on a glass slide. Then, a cut of the tissue was placed on top of the polymer film. The system was heated to $220^{\circ} \mathrm{C}$ in the Mettler Toledo HS82 hot stage. Another small sample of polymer film was added on top of the fiber, creating the polymer "sandwich" composite, and a cover slip was placed on top. A nitrogen gas flow was delivered after the composite was produced so as to prevent polymer and fiber degradation. Finally, the hot stage was turned off. The thickness of the composites prepared by this procedure was in the 100-150 $\mu \mathrm{m}$ range. 


\subsection{Optical microscopy}

After mounting the fiber/iPP composite, still within the heating stage under nitrogen atmosphere, onto the Leica DMRX optical microscope, the composite was reheated to $220^{\circ} \mathrm{C}$ for $5 \mathrm{~min}$ to erase previous history. Following the 5-min holding at $220^{\circ} \mathrm{C}$, the sample was cooled at a rate of $10^{\circ} \mathrm{C} / \mathrm{min}$ until the final crystallization temperature of $136^{\circ} \mathrm{C}$ was reached. This temperature, which was chosen after some preliminary experiments, remained constant, allowing for the sample to crystallize. Polarized light of the optical microscope, equipped with camera, was utilized to observe and record the crystallization process of the tissue/polymer composite. These observations were made between crossed polarizers using a gypsum plate. An initial picture was taken once the crystallization temperature was reached and following pictures were taken at 2-min intervals until the sample had fully crystallized.

ImageJ software was used to determine the growth rate $G$. For transcrystalline regions, the distance between the nucleation site on the fiber surface and the extremity of the transcrystalline region was measured. For bulk spherulites, the diameter of the spherulite was directly measured and then divided by two to obtain the radius. After, graphs of length vs. time were plotted and a straight line of best fit using Microsoft Excel was extrapolated. The slope of this line gave the growth rate $G$, in $\mu \mathrm{m} / \mathrm{s}$.

Isothermal quiescent crystallization in the same conditions was also performed on single films of the neat polymer as a reference.

\subsection{Scanning Electron Microscopy (SEM)}

Micrographs of both the tissues and the composites were taken with the SEM (Philips XL30 and Tescan MAIA3 ESEM) to analyze the surfaces, qualitatively observe the interfacial interactions, and identify the fibers.

\subsection{Statistical analyses}

Statistical analyses were carried out using XLStat package (Addinsoft). Multiple mean value comparison was carried out using Fisher test ( $p$ value 0.05 ). The values of the transcrystalline 
growth rate $G_{T C}$ and the spherulitic growth rate $G_{S}$ for each sample were compared using Student's paired t-test ( $\mathrm{p}$ value 0.05).

\section{Results}

\subsection{Characterization of maize samples}

The dry fractionation processes allow us to isolate particles differing in shapes and color (Figure 2): elongated white particles were mainly observed, as well round whitish-color particles (Figure 2A). More brownish and longer particles were also observed in sample F. In the same batch two different macroscopic morphologies could be observed: round particles with a foam structure (Figure $2 \mathbf{A}^{\mathbf{1}}$ ) and small elongated particles (Figure $2 \mathbf{A}^{\mathbf{2}}$ ). In comparison with the tissue morphology of maize, and based on visual and SEM observations, the tissue origin of each type of particles further included in the iPP composite was assigned. Sample $\mathbf{A}^{\mathbf{1}}$ showed a foam structure of large cells with thin cell walls, and was attributed to parenchyma cells from the pith. The particles in sample $\mathbf{A}^{\mathbf{2}}, \mathbf{B}$ and $\mathbf{C}$ were elongated, like "fibers". In cross section, the two large and prominent vessels from the metaxylem and the large lacuna of the protoxylem were observed. These three samples are assigned to vascular bundles. In the maize particle observed for sample $\mathbf{C}$ in the composite, it appears that the outermost part, the bundle sheath, is thicker than those of sample $\mathbf{A}^{\mathbf{2}}$ and $\mathbf{B}$. This vascular bundle may come from the rind, whereas sample $\mathbf{A}^{\mathbf{2}}$ and $\mathbf{B}$ come from the pith. The following samples are elongated particles and more brownish and exhibit a "shiny" and a "not shiny" side (as shown in Figure 2F). This can be related to the dissymmetrical morphology observed by SEM. The shiny face is probably the epidermis side, which is covered by a thin protective waxy layer, the not shiny face being of more foaming aspect (cortical parenchyma cells). Therefore sample $\mathbf{D}, \mathbf{E}$ and $\mathbf{F}$ are coming from the most external part of the rind. In this study, elongated particles are then constituted of different tissues of maize stem, either vascular bundles or pieces of rind. 

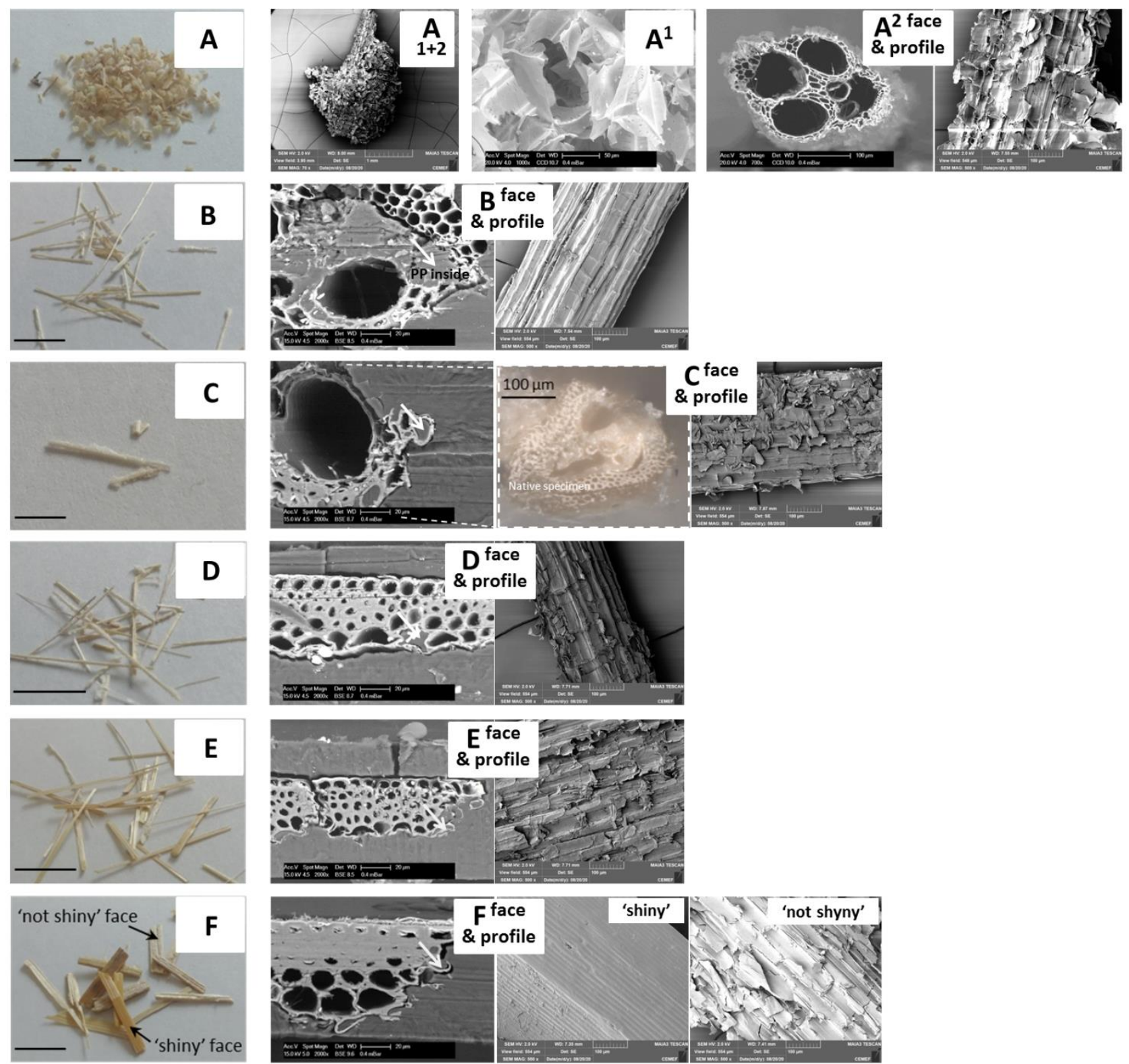

FIGURE 2 Maize samples isolated using dry fractionation processes: visual observation on the left (scale bar $1 \mathrm{~cm}$ ); SEM observations of sample/iPP composite (except for sample A) noted 'face'; on the right SEM observation of the surface of isolated native fibers noted 'profile'. Vascular bundles $\left(\mathbf{A}^{\mathbf{2}}, \mathbf{B}, \mathbf{C}\right)$, epidermis $(\mathbf{D}, \mathbf{E}, \mathbf{F})$. For the $\mathbf{A}$ sample, two types of tissue are isolated in the same fraction: on the left foam tissue coming from pith parenchyma cells $\left(\mathbf{A}^{\mathbf{1}}\right)$, on the right vascular bundle from the pith $\left(\mathbf{A}^{\mathbf{2}}\right)$. -Nota: Additional information was obtained by optical microscopy (Keyence numerical microscope VHX-6000), zoom sample C.- In 'face' composite, cell wall-like small tubular structures are shown with the highlight of a potential matrix penetration into the alveolar structure; arrows indicate the presence of iPP. 
Isothermal crystallization experiments were performed at $136^{\circ} \mathrm{C}$. This temperature was chosen because crystallization of neat iPP is relatively slow (Figure 3), with large spherulites (diameters 350-400 $\mu \mathrm{m}$ ).
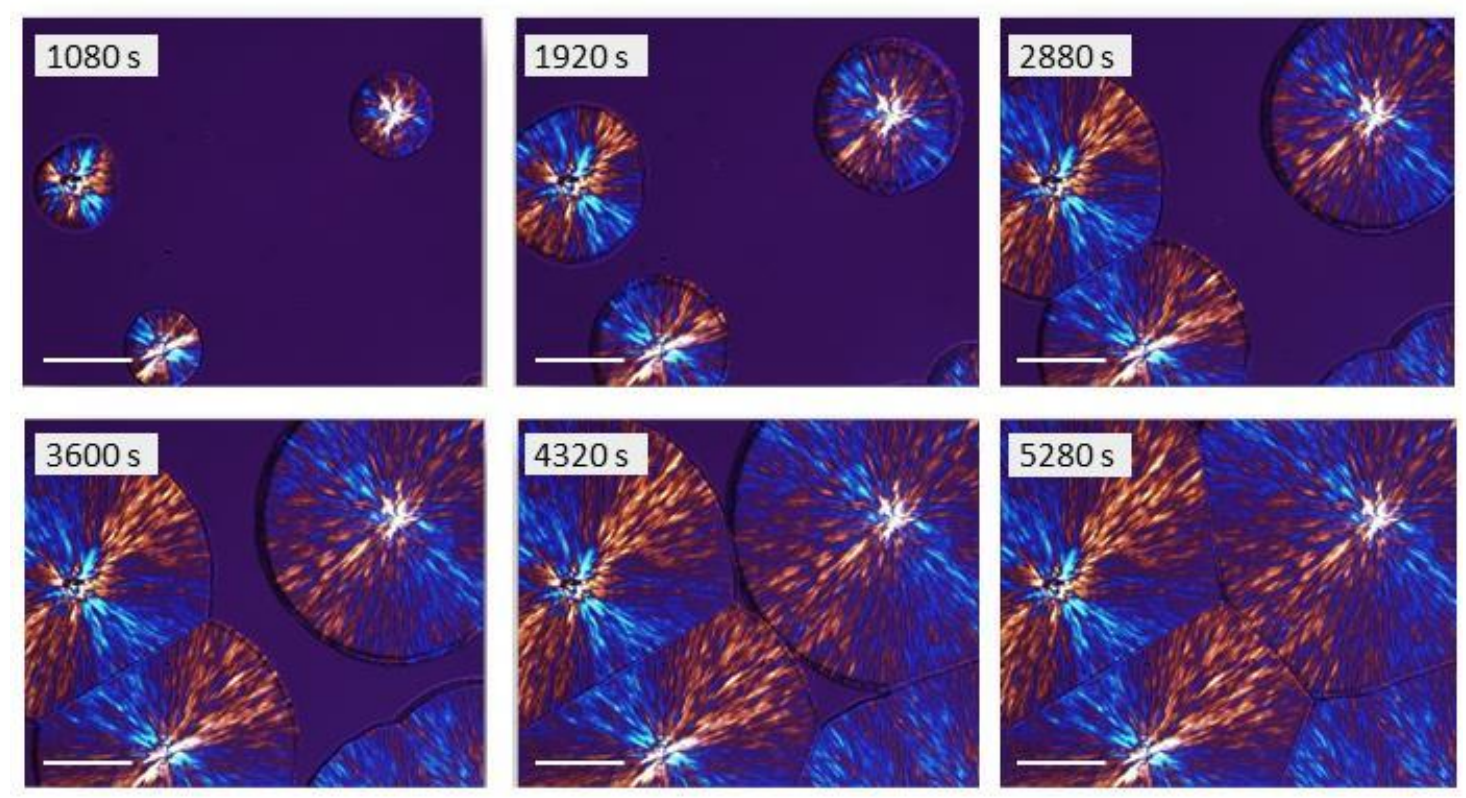

FIGURE 3 Isothermal crystallization of neat iPP at $136^{\circ} \mathrm{C}$. Observation between crossed polarizers with a gypsum plate. The scale bar represents $100 \mu \mathrm{m}$

Figure 4 presents typical results concerning composite specimens prepared as indicated in $\S$ 2.3, at the beginning of the crystallization experiment and after $18 \mathrm{~min}$ of isothermal crystallization at $136^{\circ} \mathrm{C}$. Concerning epidermis tissues, results of sample E/iPP are not given since these specimens are close to those obtained for sample $\mathbf{F} / \mathrm{iPP}$.

All the elongated fragments (vascular bundles or epidermis from the rind as shown in Figure 2) exhibit a quasi-continuous semi-crystalline sheath, except for maize $\mathbf{F}$ (epidermis)/iPP composite shiny (Figure 4d left). A more detailed analysis is delicate, since in some cases spherulitic morphologies are observed at the surface, giving a growth front made of curved segments, and in other cases, "true" transcrystalline zones, growing perpendicular to the tissue surface, are present. Let us recall that these two morphologies are not intrinsically different in nature, but results from a greater or lesser proximity of heterogeneous nuclei, i.e., from the nucleating activity of the surface. They can be observed on the same tissue (Figure 5). An additional experiment (crystallization at $140^{\circ} \mathrm{C}$ ) shows the heterogeneous distribution of nuclei 
at sample B surface (Figure 6). Other heterogeneities have been observed: different crystallization on the specimen sides (Figure 4a) or local lack of crystallization (Figure 4c).

Some specimens like sample $\mathbf{E}$ and sample $\mathbf{F}$ exhibit a "shiny" and a "not shiny" side. This has been related to their dissymmetrical morphology (Figures $2 \mathbf{E}$ and $2 \mathbf{F}$ ), the shiny being probably the epidermis side, covered by a thin protective waxy layer. Tweezers were used to peel layers of either a shiny or not shiny side to use in the composite. Clearly, very different crystallization behaviors are observed (Figure 4d): for equivalent crystallization conditions, surface nucleation in the composite made of the shiny side is particularly low, probably because of the abovementioned surface composition.

Regarding the foam part (sample $\mathbf{A}^{\mathbf{1}}$ ) (Figure 4e left), the loose surface does not induce transcrystallinity, as the entities do not grow in a columnar front. Rather, the surface is capable of inducing high nucleation density, but the direction of growth is more varied and random. Indeed, numerous spherulites seem to be agglomerated around the particle.
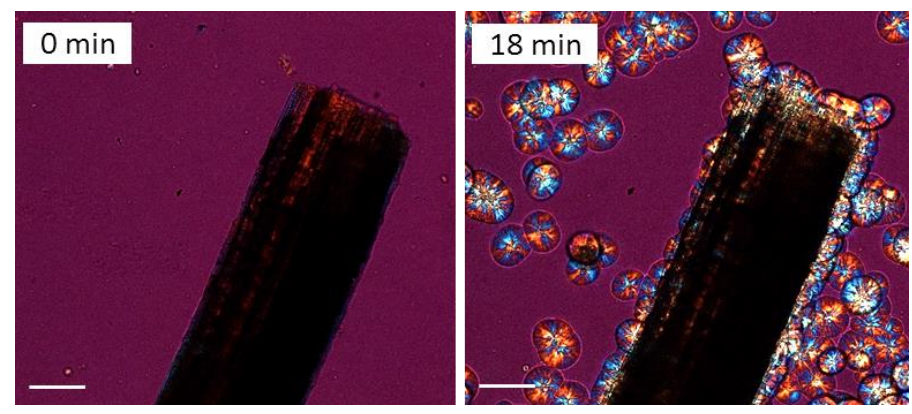

a) Maize sample $\mathbf{B} / \mathrm{iPP}$ composite

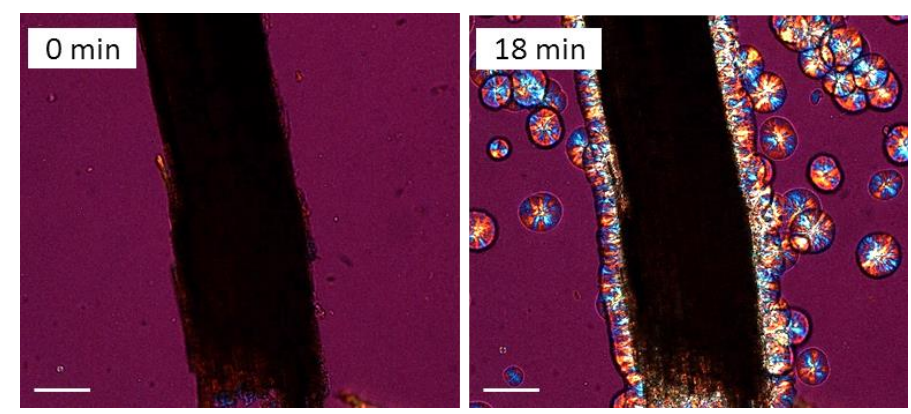

b) Maize sample $\mathbf{D} / \mathrm{iPP}$ composite 

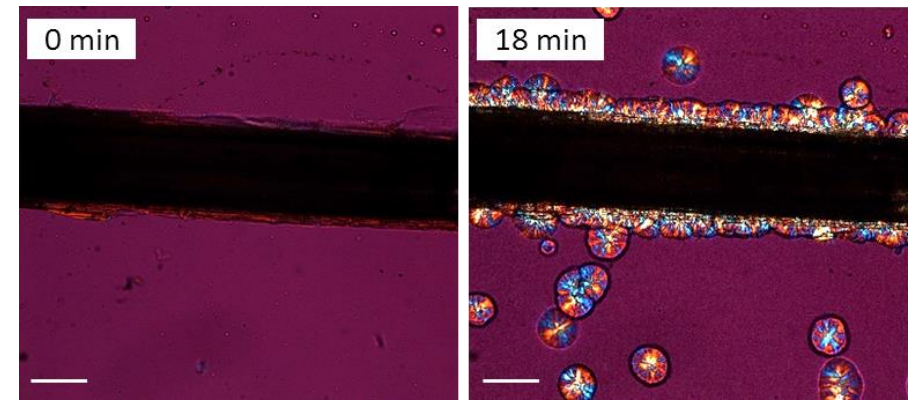

c) Maize sample $\mathbf{C} / \mathrm{PPP}$ composite
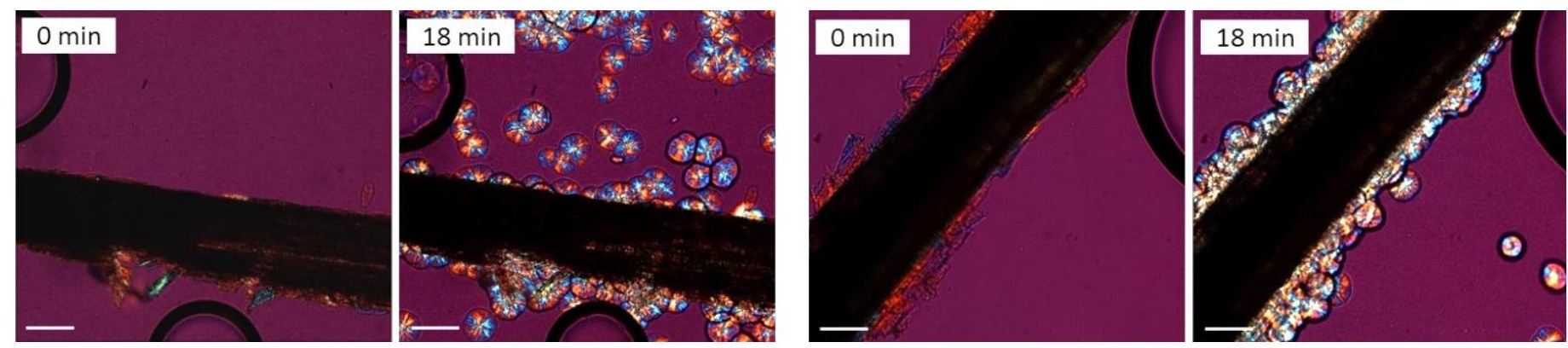

d) Maize sample F/iPP composite: shiny (left) and not shiny (right)
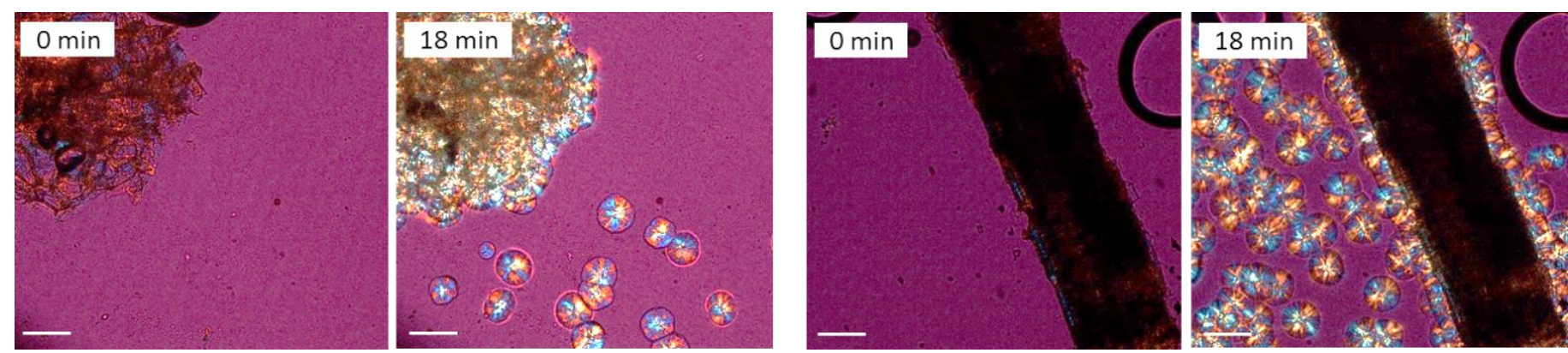

e) Maize sample $\mathbf{A}^{\mathbf{1}}$ (foam)/iPP composite (left), and sample $\mathbf{A}^{\mathbf{2}}$ (fiber)/iPP composite (right)

FIGURE 4 Isothermal crystallization at $136^{\circ} \mathrm{C}$ of Maize/iPP composites: a) sample $\mathbf{B} / \mathrm{iPP}$ composite; b) sample D/iPP composite; c) sample C/iPP composite; d) sample F/iPP composite: shiny (left) and not shiny (right); e) sample A/iPP composite: sample $\mathbf{A}^{\mathbf{1}}$ (left) and sample $\mathbf{A}^{\mathbf{2}}$ (right). The scale bar represents $100 \mu \mathrm{m}$ 


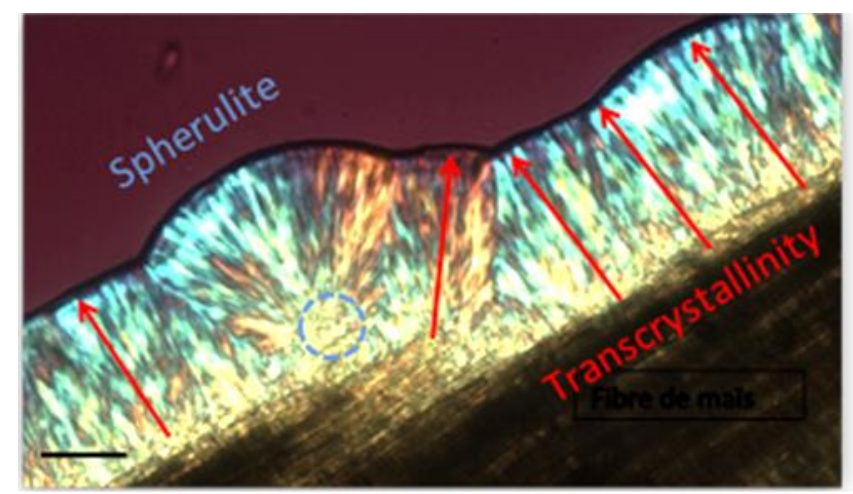

FIGURE 5 Surface crystallization at $136^{\circ} \mathrm{C}$ on the sample $\mathbf{F}$ shiny. The arrows indicate the local directions of growth. The scale bar represents $50 \mu \mathrm{m}$

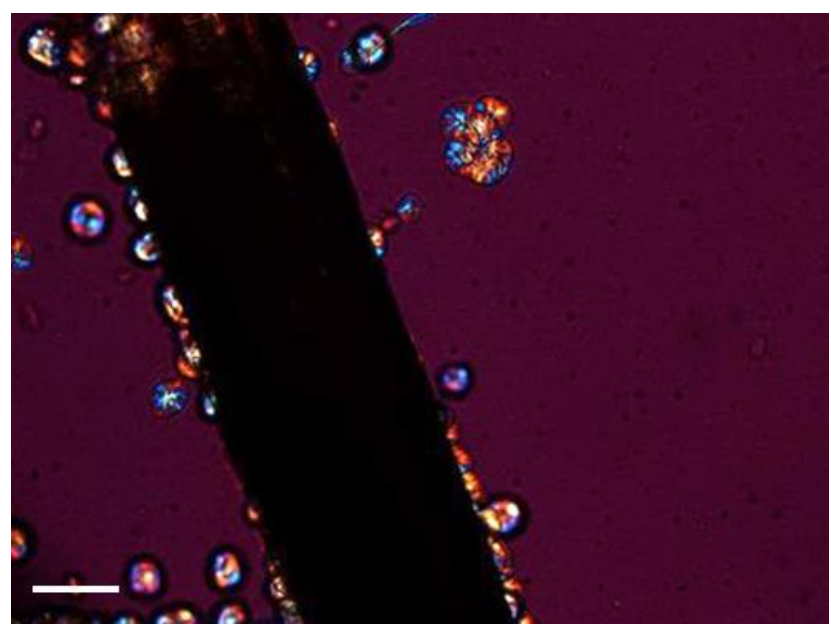

FIGURE 6 Isothermal crystallization at $140^{\circ} \mathrm{C}$ of sample $\mathbf{B} / \mathrm{iPP}$ composite. The scale bar represents $50 \mu \mathrm{m}$

\subsection{SEM observation of the interface}

Supplementary information can be drawn from the SEM pictures of Figure 2. One can observe in Figure $2 \mathbf{E}$ that in the rougher, not shiny side, the polypropylene seems to bind better with the tissue surface than in the shiny side, for which there is a gap between the surface and the polymer. It may indicate that the interfacial interactions between the rough side and the polymer are better than those of the shiny side and the polymer, which is consistent with the different crystallization behaviors described above. This could orignate from a difference in chemical composition (e.g., the existence of a waxy external layer), as well as from different surface topologies: the shiny side is flatter, while the not shiny one is rougher and provides more surface area for interactions between the polymer and the tissue to occur. From the SEM image of Figure $2 \mathbf{F}$, one can remark that, as for sample $\mathbf{E}$, the rougher side (bottom) seems to bind more 
easily to the polypropylene than the smoother side (top). However, on the shiny side, there appears a white fluff, which is unknown, perhaps some contamination to the tissue sample. In Figure 2D, gaps between the polymer and tissue surface are present on both sides, suggesting that the interfacial interactions are weak, even in the rougher side. In the above-mentioned experiments, the polymer does not penetrate much in the tissue pores, corresponding either to the metaxylem or protoxylem in the vascular bundle. In sample B/iPP composites (Figure $2 \mathbf{B}$ ), an interesting observation of is that the polymer partially fills the inside of the tissue (in the vessels). It is also observed to a lesser extent in other composites (see arrows in Figure 2). It may seem surprising because of the high viscosity of the polymer melt, even though the MFI of the present polymer is high. It could be due to the polymer flow during the preparation of the sandwich specimen, which is also likely to have damaged the tissue. Nuez et al. ${ }^{[28]}$ observed the same potential matrix penetration into the alveolar structure in injection-molded polypropylene composites with flax shives. They proposed a basic micromechanical model discussion on the capacity of cell wall-like small tubular structures highlighting the mechanical reinforcing potential of hollow fibers.

\subsection{Growth rate measurements}

The growth-rate values vary, although only slightly, between different tissues for both transcrystalline and bulk regions. Since the growth rate is a function of temperature, and that all experiments were performed at the same temperature of $136^{\circ} \mathrm{C}$, the growth rates of all samples are expected to be the same. However, it is interesting to note that for all experiments, the transcrystalline growth rate $G_{T C}$ is slightly higher than the spherulitic growth rate $G_{S}$ in the bulk for the same sample. It was then necessary to check if this trend is statistically significant and not due to systematic errors.

To check these preliminary results, three typical tissues were selected: vascular bundles from pith (sample B), vascular bundles from rind (sample $\mathbf{C}$ ) and cortical parenchyma (sample $\mathbf{F}$ not shiny). Eight different crystallization experiments at $136^{\circ} \mathrm{C}$ were done for each type of specimen, and $G_{S}$ and $G_{T C}$ were measured. The results of these measurements are displayed in Table 1. 
TABLE 1 Comparison of $G_{S}$ and $G_{T C}$ in $\mu \mathrm{m} / \mathrm{s}$ for three types of composites. $G_{S}$ values for neat iPP

\begin{tabular}{|c|c|c|c|c|c|c|c|}
\hline & \multicolumn{2}{|c|}{ Sample B } & \multicolumn{2}{c|}{ Sample C } & \multicolumn{2}{c|}{ Sample F not shiny } & iPP \\
\cline { 2 - 8 } & $G_{S}$ & $G_{T C}$ & $G_{S}$ & $G_{T C}$ & $G_{S}$ & $G_{T C}$ & $G_{S}$ \\
\hline Exp. 1 & 0.0375 & 0.0373 & 0.0353 & 0.0417 & 0.0374 & 0.0427 & 0.0411 \\
\hline Exp. 2 & 0.0361 & 0.0369 & 0.0394 & 0.0413 & 0.0364 & 0.0398 & 0.0389 \\
\hline Exp. 3 & 0.0400 & 0.0410 & 0.0366 & 0.0409 & 0.0373 & 0.0388 & 0.0395 \\
\hline Exp. 4 & 0.0394 & 0.0399 & 0.0388 & 0.0385 & 0.0386 & 0.0416 & 0.0392 \\
\hline Exp. 5 & 0.0396 & 0.0408 & 0.0352 & 0.0367 & 0.0369 & 0.0379 & 0.0411 \\
\hline Exp. 6 & 0.0398 & 0.0414 & - & 0.0364 & 0.0363 & 0.0381 & \\
\hline Exp. 7 & 0.0384 & 0.0413 & 0.0390 & 0.0437 & 0.0349 & 0.0375 & \\
\hline Exp.8 & 0.0373 & 0.0393 & 0.0356 & 0.0390 & 0.0384 & 0.0392 & \\
\hline Mean & 0.0385 & 0.0397 & 0.0371 & 0.0398 & 0.0370 & 0.0395 & 0.0400 \\
\hline SSD & 0.0014 & 0.0018 & 0.0019 & 0.0026 & 0.0012 & 0.0018 & 0.0011 \\
\hline$S E$ & 0.0005 & 0.0006 & 0.0007 & 0.0009 & 0.0004 & 0.0007 & 0.0005 \\
\hline$\%$ & 1.31 & 1.58 & 1.91 & 2.27 & 1.14 & 1.65 & 1.19 \\
\hline
\end{tabular}

A simple statistical analysis is also presented in Table $1 . x_{i}$, with $i=1$ to $n$, denoting the value of growth rate in the $i^{\text {th }}$ experiment, we calculate:[29]

- the sample mean (M): $\bar{x}=\frac{1}{n} \sum_{i=1}^{n} x_{i}$

- the sample standard deviation (SSD): $s=\sqrt{\frac{\sum_{i=1}^{n}\left(x_{i}-\bar{x}\right)^{2}}{n-1}}$

- the standard error of the mean (SE): $S E=\frac{S}{\sqrt{n}}$

- the percentage of error: $\%=\frac{S E}{\bar{x}}$

The results of these calculations are given in Table 1 and illustrated graphically in Figure 7. To confirm the results of this first analysis, Fisher's test and Student's paired t-tests with a threshold value $\mathrm{p}=0.05^{[29]}$ were applied to the data of Table 1. The results for Fisher's test, shown in Table 2, are interpreted as follows: when average values of growth rate are followed by the same superscript, they are considered as not significantly different. On the contrary, if the superscripts are different, the difference between them is significant. 
TABLE 2 Fisher's test applied to the data of Table 1. Comparison of $G_{S}$ and $G_{T C}$ in $\mu \mathrm{m} / \mathrm{s}$ for three types of composites and $G_{S}$ values for neat iPP. Mean values with same superscript letter are not significantly different (Fisher test, $\mathrm{p}>0.05$ )

\begin{tabular}{|c|c|c|}
\hline & $\begin{array}{c}G_{S} \\
(\mu \mathrm{m} / \mathrm{s})\end{array}$ & $\begin{array}{c}G_{T C} \\
(\mu \mathrm{m} / \mathrm{s})\end{array}$ \\
\hline Sample B & $0.0385^{a b}$ & $0.0397^{a}$ \\
\hline Sample C & $0.0371^{b}$ & $0.0398^{a}$ \\
\hline Sample F not shiny & $0.0370^{b}$ & $0.0395^{a}$ \\
\hline iPP & $0.0400^{a}$ & \\
\hline
\end{tabular}

These combined analyses lead to the following conclusions:

- the $G_{T C}$ of the three specimens are not significantly different, and not significantly different from the growth rate in neat iPP;

- The values of $G_{S}$ for sample $\mathbf{C}$ and $\mathbf{F}$ are equivalent, but different from those for neat iPP;

- The means of $G_{S}$ and $G_{T C}$ are significantly different from a statistical point of view for each sample, based on Student's paired t-tests, confirming that $G_{T C}>G_{S}$.

This raises a problem, as for a given iPP, growth rate should depend uniquely on crystallization temperature, and consequently one should obtain in Table 2 average values not significantly different. This requires a more in depth analysis. In a first step, we will analyze from a theoretical point of view which physical parameters are likely to modify the value of growth rate. This analysis will be based on Hoffman's theory. 


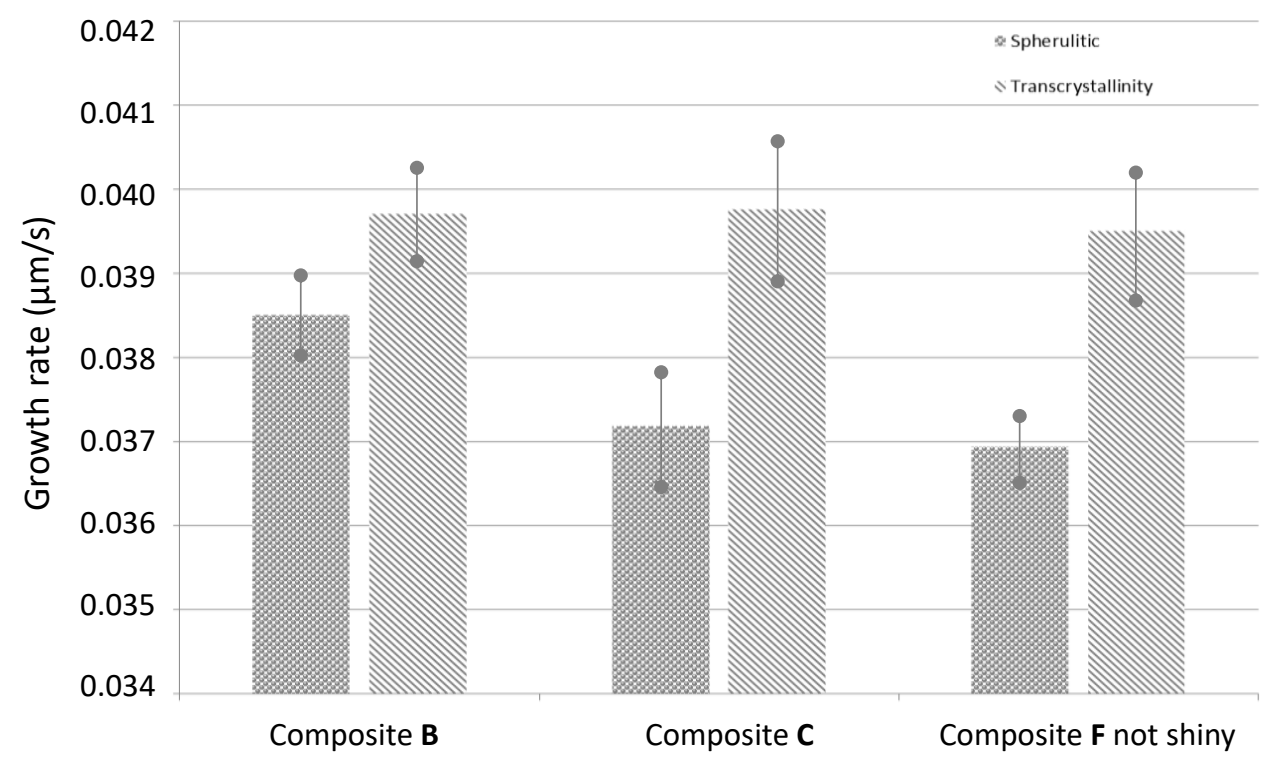

FIGURE 7 Comparison between the growth rates of bulk spherulites and transcrystalline regions

Hoffman and co-workers proposed and repeatedly revisited a kinetic theory of growth based on a mechanism of secondary nucleation. ${ }^{[30-33]}$ They distinguish three different modes of lamellar growth, called regime I, regime II and regime III, respectively, which differ by the deposit mechanisms of molecular stems on the growth front. For these three regimes, the growth rate $G$ of a crystalline entity (e.g., a spherulite) is described by the general expression:

$$
G\left(T_{c}\right)=G_{0}^{i} \exp \left(-\frac{U^{*}}{R\left(T_{c}-T_{\infty}\right)}\right) \exp \left(-\frac{K_{g}^{i}}{T_{c}\left(T_{m}^{0}-T_{c}\right)}\right)
$$

$T_{c}$ is the crystallization temperature and $\Delta T$ is the degree of undercooling: $\Delta T=T_{m}^{0}-T_{c}$, with $T_{m}^{0}$ the equilibrium melting temperature. $U^{*}$ is the activation energy for the transport of molecular segments across the melt/crystal interface and $T_{\infty}$ is the temperature at which molecular mobility ceases. Usually, $U^{*}=6270 \mathrm{~J} \mathrm{~mol}^{-1}$ and $T_{\infty}=T_{g}-30, T_{g}$ being the glass transition temperature. $R$ is the gas constant, equal to $8.314 \mathrm{~J} \mathrm{~mol}^{-1} \mathrm{~K}^{-1} \cdot G_{0}^{i}$ and $K_{g}^{i}$ are constant for a given regime $(i=\mathrm{I}, \mathrm{II}, \mathrm{III})$. 
We did not determine the values of the physical parameters of equation (5) for the iPP used here, but we previously studied a polymer which is very close. ${ }^{[34]}$ The values for the latter polymer will be used here, as our purpose is not to calculate absolute values of $G$, but only variations. Hence, $T_{m}^{0}=208{ }^{\circ} \mathrm{C}$ and $T_{\infty}=-51^{\circ} \mathrm{C}$. The transition from to regime III to regime II occurs at about $137^{\circ} \mathrm{C}$, regime II corresponding to the higher temperature range. Therefore, the values for regime III will be used: $\ln G_{0}^{I I I}(\mu \mathrm{m})=26.42$ and $K_{g}^{I I I}=7.71 \times 10^{5} \mathrm{~K}^{2}$. Calculations have been done for a $G$ value close to those of Table 1: $G=0.0361 \mu \mathrm{m}$ at $T_{c}=$ $134.3{ }^{\circ} \mathrm{C}$.

The calculations show that:

- a decrease of $T_{c}$ by $0.3{ }^{\circ} \mathrm{C}$ induces an increase of $G$ of $0.0030 \mu \mathrm{m} / \mathrm{s}$, which is close to the maximum difference between the means of $G_{S}$ and $G_{T C}$, and also close to the maximum difference between the mean growth rates in the bulk, observed in Table 1 . Therefore, this difference could result from local temperature changes. However, these changes are small and can be compared to the performance of the hot stage: according to the HS82 specifications, the temperature resolution is $0.1{ }^{\circ} \mathrm{C}$ and the temperature accuracy is between $\pm 0.4{ }^{\circ} \mathrm{C}$ and $\pm 0.8{ }^{\circ} \mathrm{C}$ according to the temperature range. Then, the origin of these changes due to the presence of the filler should be understood: crystallization is isothermal and has a long duration.

- an increase of $\Delta T$ of $0.2-0.3{ }^{\circ} \mathrm{C}$ induces an increase of $G$ between 0.0026 and $0.0040 \mu \mathrm{m} / \mathrm{s}$. $T_{c}$ being fixed to $134.3{ }^{\circ} \mathrm{C}$, this increase is obtained by increasing $T_{m}^{0} . T_{m}^{0}$ is modified when an additional substance, acting as diluent, is dissolved in the polymer melt. The effect is generally a depression of the equilibrium melting temperature, which is not pertinent here. Conversely, an increase of $T_{m}^{0}$ is obtained, if the polymer melt is oriented or disentangled. ${ }^{[10]}$ Disentanglement plays also a role on the transport of molecular segments and equation (5) should be modified to quantify this effect. ${ }^{[33]}$ Roughly speaking, the lower the number of entanglements along the chains, the higher the growth rate at high crystallization temperatures. This was checked by Psarski et al., ${ }^{[35]}$ who studied the crystallization of polyethylene from a melt with lowered chain entanglements. According to the crystallization temperature, the growth rate increase varied between 22 and $45 \%$. 
In the present case, some local orientation could have been created during the preparation of the sandwich specimens, but it should have been relaxed during the heat treatment at $220^{\circ} \mathrm{C}$ before crystallization.

- a small decrease of $K_{g}^{I I I}$ induces a significant increase of $G: 0.0025 \mu \mathrm{m} / \mathrm{s}$ if $K_{g}^{I I I}=7.69 \times 10^{5} \mathrm{~K}^{2}$ and $0.0038 \mu \mathrm{m} / \mathrm{s}$ if $K_{g}^{I I I}=7.68 \times 10^{5} \mathrm{~K}^{2}$. As $K_{g}^{I I I}$ is proportional to the extremity surface $\sigma_{e},{ }^{[33]}$ this could reflect a modification of the contact between the crystal and the surrounding melt, resulting from the presence of the fiber.

At first glance, the statistical analysis shows that the $G_{T C}$ of the three specimens are not significantly different, and not significantly different from the growth rate in the neat iPP. Therefore, a straightforward conclusion could be that there is no effect of the tissues on the growth rate and that temperature actually governs growth. We think that this comparison of average values is not pertinent since the growth rate in the bulk, which is the reference, may vary from an experiment to another, as shown in Table 1. For this reason, we think that it is better to compare $G_{S}$ and $G_{T C}$ measured on the same composite specimen during the same experiment. This procedure leads to significant differences between them for the three samples. All these tentative explanations to understand these differences more or less involve a slight physical or chemical modification of the polymer melt near the tissue. The orders of magnitude given by our calculations are probably correct, but it would desirable to do them again with the true kinetic parameters to get closer to reality. For instance, in the present work, spherulites observed at $136^{\circ} \mathrm{C}$ in Figure 3 are of negative birefringence, which means that crystallization already occurred in regime II. ${ }^{[36]}$

Finally, the differences in $G_{S}$ values remain difficult to understand. They could be due to specimen preparation: difference between single film and sandwich, local orientation created by flow during specimen preparation but not completely relaxed by subsequent heat treatment... This remains speculative.

4 Discussion and conclusion 
Different maize tissues were obtained by dry fractionation processes. A first challenge was to isolate maize stem tissues, to perfectly locate each part in the maize and to perform a first morphological characterization without any additional concern. The morphological features of the tissues were identified by optical and scanning electron microscopies. Samples from pith parenchyma, vascular bundles and rind epidermis were isolated. For each type of tissue, a small fragment was sandwiched between two films of isotactic polypropylene, and the composite was subjected to isothermal crystallization experiments, observed by optical microscopy. An advantage of this procedure is to use only a small quantity of tissue. Second advantage is to work on a 'model' system, matrix and maize tissues being well defined.

Heterogeneous nucleation at the surface of maize tissues has been investigated. In all cases, more or less numerous semi-crystalline entities originate from the tissue surface, indicating a moderate nucleating activity. Observations by scanning electron microscopy have shown in some cases the weakness of the interfacial interactions between filler and matrix. It is not surprising since no coupling agent like maleic anhydride grafted polypropylene MA-g-PP was used. It was our choice, in order to study the intrinsic nucleating activity of the tissues, and to avoid any chemical treatment for environmental respect.

Different crystallization behaviors have been observed as a function of the type of tissue. In the case of the so-called foam structure, made of pith parenchyma cells, the semi-crystalline entities do not grow in a columnar front because of the loose surface of the particle. Instead, numerous spherulites seem to be agglomerated around the particle. In tissues coming from the rind, a dissymmetrical behavior is observed: surface nucleation on the external epidermis side is much lower. For other specimens, it is more difficult to identify differences. A first reason is perhaps that they are constituted by the same type of tissue, e.g., vascular bundles mentioned several times in Figure 2, and thus the same surface composition. In fact, the surface of vascular bundles is perhaps always constituted by a sclerenchyma sheath, which is supposed to be relatively homogeneous in terms of composition. Then, even for an individual sample in a given experiment, a non-uniform distribution of surface nuclei has been observed. It can also be mentioned that fine SEM analysis shows that the bundles of sample B are "clean" with little adherent parenchyma. Therefore the sclerenchyma sheath would be on the surface. Between sample $\mathbf{B}$ and sample $\mathbf{C}$ the thickness of the sheath changes, but its composition may not. One 
could then assume that the composition is similar in the sclerenchyma of the bundles of the pith and the rind of the plant.

To complete the microscopic observations, it would be desirable to quantify the influence of the tissues on the overall crystallization kinetics. This is in principle possible in our experiments by optical microscopy. The average transmitted intensity $I(t)$ or DLI (Depolarized Light Intensity) is deduced from the grey level analysis using the image analysis software (Image $J$ ). The relative crystallinity $\alpha(t)$ is then calculated by:

$$
\alpha(t)=\frac{I(t)-I_{0}}{I_{f}-I_{0}}
$$

where $I_{0}$ and $I_{f}$ are the initial and final intensities, respectively. This technique was applied in our experiments. However, at this stage, it was not possible to draw reliable conclusions from these experiments. One reason is the complexity of the system under investigation: polymer melt, growing spherulites, the filler as a dark patch with thin semi-crystalline layers at its surfaces. Furthermore, air or water bubbles formed from pockets within the tissue disturb the light intensity measurements. From a more general point of view, the determination of crystallization kinetics from the measurement of transmitted light intensity is a matter of debate. Indeed, it has been checked for this type of polypropylene that the kinetics obtained by this method is exactly the same as the one recorded by differential scanning calorimetry (DSC), for crystallization during a cooling at $10^{\circ} \mathrm{C} / \mathrm{min}$. However, some discrepancies might occur during isothermal crystallizations at relatively high temperature, i.e., of relatively long duration, as here with an isothermal crystallization at $136^{\circ} \mathrm{C}$. Light intensity measurements might lead to apparently shorter crystallization times, because they might not be always able to capture some slight variations of crystallinity at the end of crystallization.

In our work, growth rates of surface layers were generally higher that the growth rates of bulk spherulites. These differences are small and can be questioned. They seemed to be significant in some cases. They were discussed within the frame of kinetic theory of growth. ${ }^{[33]}$ Growth rate differences were also observed in the case of polyester/cellulose nanocrystal composite fibers by Huang et al. ${ }^{[37]}$ The discussion of their results was based on the same elements as in the present work. 
Additionally, because maize tissue is chemically heterogeneous, at the interface may appear different types of 'physico-chemical defects' that will induce different types of heterogeneous nucleation and 'nucleation confinement' effect. Locally, such heterogeneity in structure (native structure or biodegradation/combustion) would modify fluid mechanics and also maybe thermal gradients. This is a very interesting issue that needs further local analysis with better controlling interface physico-chemistry together with aspect surface of bio-fibers (see in Figure 2 the surface heterogeneities of the fibers) and confinement-induced local heterogeneous fluid mechanics and thermal gradients.

Crystallization mechanisms (nucleation and growth confinement) are of mechano-chemophysical interest. In a further step, the chemical composition of the specimens should be taken into account. Following previous work (see Introduction), an important parameter seems to be the relative proportion of cellulose and lignin. The distribution of cellulose and lignin inside a maize stem is complex, as shown by FASGA staining procedure. ${ }^{[38]}$ Therefore, the correlation between morphology, chemical composition and nucleation activity remains a difficult task. In the pith region, parenchyma cells contain more lignin and the neighborhood of vascular bundles more cellulose. ${ }^{[38]}$ This could be correlated to some of our observations concerning the pith: transcrystalline zones around fibrillar specimens and spherulites around "foam" specimens. Nevertheless, the situation is changing, when one moves towards the external regions, which shows the necessity of an in-depth analysis. The difficulty of relating at a very small scale nucleation and growth to the physical and biochemical characteristics of the surface is the very large heterogeneity of these properties which may vary deeply from one place to another in a plant fragment (it is not depending on fiber arrangements of fiber sizes in the present issue). The purpose of our work was to minimize these effects by carefully selecting small tissue fragments. This procedure enabled us to evidence the importance of the type of tissue present at the surface of a plant fragment. However, to fully understand the mechanisms at stake would require the measurements of parameters such as the exact polymers at the surface, the topography of the surface (roughness, presence of voids or channels), the surface tension and its components. There is no secure way to perform this at a very local scale. This should clearly be a target for future investigations.

The present work is a first step to demonstrate that different maize tissues affect both nucleation and growth of isotactic polypropylene in different ways, for example the difference in nucleation ability between "shiny" and "not shiny" surfaces. 


\section{Acknowledgments}

The authors acknowledge Amélie Breysse for technical assistance in maize tissue isolation and the plant agro-resources processing platform (PLANET) of IATE group (Ingénierie des Agropolymères et Technologies Emergentes, Montpellier, France). The authors acknowledge Suzanne Jacomet for technical assistance in SEM investigation (MINES Paris PSL, Sophia Antipolis, France).

Part of this work was achieved within the framework of the internship of Vivian Song supported by the MIT-France program between the Massachusetts Institute of Technology, USA and France, which is kindly acknowledged.

The authors also thank Mr. Patrick Coels for constant help and Dr. Pierre Montmitonnet for judicious advice.

\section{References}

[1] T. Gurunathann, S. Mohanty, S. K. Nayak, Composites Part A. Appl. Sci. Manufacturing 2015, 77,1 .

[2] M. K. Deyholos, S. Potter, Biocatal. Agric. Biotechnol. 2014, 3, 53.

[3] M. P. M. Dicker, P. F. Duckworth, A. B. Baker, G. Francois, M. K. Hazzard, P. M. Weaver, Compos. A: Appl. Sci. Manuf. 2014, 56, 280.

[4] P. M. Ramamoorthy, M. Skrifvars, A. Persson, Polym. Rev. 2015, 55, 107.

[5] V. K. Thakur, M. K. Thakur, R. K. Gupta, Int. J. Polym. Anal. Charact. 2014, 19, 256.

[6] T. Väisänen, O. Das, L. Tomppo, J. Cleaner Product. 2017, 149, 582.

[7] J. L. Thomason, A. A. Van Rooyen, J. Mater. Sci. 1992, 27, 897.

[8] N. E. Zafeiropoulos, C. A. Baillie, F. L. Matthews, Composites : Part A 2001, 32, 525.

[9] A. Arbelaiz, B. Fernández, J. A. Ramos, I. Mondragon, Thermochim. Acta 2006, 440, 111.

[10] J. M. Haudin, Crystallization in processing conditions, in Handbook of polymer crystallization, E. Piorkowska, G. C. Rutledge editors, John Wiley \& Sons, Inc., Hoboken, New Jersey 2013, 433.

[11] D. R. Fitchmun, S. Newman, J. Polym. Sci. Part A-2 1970, 8, 1545.

[12] C. Mathieu, A. Thierry, J. C. Wittmann, B. Lotz, Polymer 2000, 41, 7241.

[13] N. Ning, S. Fu, W. Zhang, F. Chen, K. Wang, H. Deng, Q. Fu, Prog. Polym. Sci. 2012, 37, 1425 . 
[14] H. Quan, Z. M. Li, M. B. Yang, R. Huang, Compos. Sci. Technol. 2005, 65, 999.

[15] K. A. Iyer, A. M. Flores, J. M. Torkelson, Polymer 2015, 75, 78.

[16] V. Khoshkava, H. Ghasemi, M. R. Kamal, Thermochim. Acta 2015, 608, 30.

[17] D. G. Gray, Cellulose 2008, 15, 297.

[18] J. Girones, L. T. T. Vo, J. M. Haudin, L. Freire, P. Navard, Polymer 2017, 127, 220.

[19] D. G. Gray, J. Polym. Sci, Polym. Lett. Ed. 1974, 12, 509.

[20] G. George, K. Joseph, E. R. Nagarajan, E. T. Jose, M. Skrifvars, Compos. A: Appl. Sci. Manuf. 2013, 48, 110.

[21] P. V. Joseph, K. Joseph, S. Thomas, C. K. S. Pillai, V. S. Prasad, G. Groeninckx, M. Sarkissova, Compos. A: Appl. Sci. Manuf. 2003, 34,253.

[22] A. R. Sanadi, D. F. Caulfield, Compos. Interfaces 2000, 7, 31.

[23] D. T. Quillin, D. F. Caulfield, J. A. Koutsky, J. Appl. Polym. Sci. 1993, 50, 1187.

[24] S. Borysiak, B. Doczekalska, Holz als Roh- und Werkst. 2006, 64, 451.

[25] B. G. Lee, S. Lee, B. K. Via, J. Appl. Polym. Sci. 2010, 116, 1958.

[26] J. M. Haudin, S. A. E. Boyer, Int. Polym. Proc. 2016, 32, 545.

[27] C. Mayer-Laigle, L. Haurie Ibarra, M. Palumbo, A. Breysse, F. Mabille, A. Lacasta, C. Barron, Corn pith as insulating biomaterial: from biomass fractionation to composite production, Proc. 4th Int. Conf. Biobased Mater. Compos., Nantes, 2017; C. Mayer-Laigle, A. Breysse, F. Mabille, C. Barron, to be submitted to Industrial Crops and Products 2020.

[28] L. Nuez, J. Beaugrand, D. U. Shah, C. Mayer-Laigle, A. Bourmaud, P. D’Arras, C. Baley, Ind. Crop. Prod. 2020, 148, 112324.

[29] L. Lebart, A. Morineau, J. P. Fénelon, Traitement des données statistiques : méthodes et programmes, Dunod, Paris 1979.

[30] J. I. Lauritzen Jr., J. D. Hoffman, J. Res. Nat. Bur. Std. 1960, 64A, 73.

[31] J. D. Hoffman, L .J. Frolen, G. S. Ross, J. I. Lauritzen Jr., J. Res. Nat. Bur. Std. 1975, 79A, 671.

[32] J. D. Hoffman, Polymer 1983, 24, 3.

[33] J. D. Hoffman, R. L. Miller, Polymer 1997, 38, 3151.

[34] S. A. E. Boyer, P. Robinson, P. Ganet, J. P. Melis, J. M. Haudin, J. Appl. Polym. Sci. 2012, $125,4219$.

[35] M. Psarski, E. Piorkowska, A. Galeski, Macromolecules 2000, 33, 916.

[36] B. Monasse, J. M. Haudin, Colloid Polym. Sci. 1985, 263, 822.

[37] J. Huang, C. J. Xua, D. F. Wua, Q. L. Lv, Carbohydr. Polym. 2017, 167, 105. 
[38] Y. Zhang, S. Legay, Y. Barriere, V. Mechin, D. Legland, J. Agric. Food Chem. 2013, 61, 3186. 